\title{
EFEKTIVITAS KINERJA JURUSITA PAJAK DALAM MELAKUKAN PENAGIHAN PAJAK PADA KANTOR PELAYANAN PAJAK PRATAMA MANADO DAN KANTOR PELAYANAN PAJAK PRATAMA BITUNG
}

\author{
Megi Afrilia \\ Jullie J. Sondakh \\ Robert Lambey \\ Fakultas Ekonomi dan Bisnis \\ Universitas Sam Ratulangi Manado \\ Email: megiafrilia74@gmail.com
}

\begin{abstract}
In the effort of securing national revenue the work of Tax Bailiff is needed, for if everything is delegated to the Tax Payer, then the achievement of targets could not be guaranted. When making tax collection, performance of Tax Bailiff are affected by various things: limited numbers of Tax Bailiff, unkown address of the Tax Payers or Tax Guarantors, and more. The purpose of this study is to determine the level of performance evectiveness of the Tax Bailiff when making tax collection at Manado Tax Office and Bitung Tax Office. The research needs quantitative data, uses primary data, and uses descriptive analysis research method.The result indicates the level of performance evectiveness of Tax Bailiff by the year of 2014 at Manado Tax Office are 56,82\% (non-efective), while Bitung Tax Office are 47,83\% (non-evective). The level of performance evectiveness of Tax Bailiff by the year of 2015 at Manado Tax Office are 51,37\% (non-evective), while Bitung Tax Office are 63,52\% (lessevective).
\end{abstract}

Keywords: Tax Collecting, Tax Bailiff, Tax Due.

\section{Latar Belakang}

\section{PENDAHULUAN}

Tujuan negara adalah untuk melindungi segenap bangsa, memajukan kesejahteraan umum, mencerdaskan kehidupan bangsa, dan ikut serta dalam melaksanakan ketertiban dunia yang berdasarkan kemerdekaan, perdamaian abadi, dan keadilan sosial. Hal ini dijelaskan dalam pembukaan UUD 1945. Memajukan kesejahteraan umum berarti memajukan suatu tingkat kehidupan masyarakat secara optimal dan memenuhi kebutuhan dasar kehidupan manusia. Semuanya itu dapat terwujud dengan melaksanakan pembangunan di segala bidang. Pembangunan Nasional adalah kegiatan yang berlangsung secara terus-menerus dan berkesinambungan yang bertujuan untuk meningkatkan kesejahteraan rakyat baik materil maupun spiritual (Lawal, 2011: 238).

Membayar pajak adalah kewajiban setiap warga negara, namun pada hakekatnya setiap orang enggan untuk membayar pajak. Hal ini dapat dibuktikan dengan adanya tunggakan pajak sebagai akibat wajib pajak tidak melaksanakan kewajiban perpajakan sesuai peraturan.Wajib pajak yang sadar akan kewajiban perpajakannya seharusnya memenuhi sendiri kewajiban pajaknya, dimulai dengan mendaftarkan diri sebagai Wajib Pajak, menghitung, memotong, menyetor, dan atau melapor sendiri segala kewajiban pajaknya pada petugas pajak atau Jurusita Pajak.

Masalah perpajakan bukan hanya masalah pemerintah saja dan pihak-pihak yang terkait di dalamnya akan tetapi masyarakat juga sangat mempunyai kepentingan yang sama untuk mengetahui masalah perpajakan Indonesia. Menurut Aruna (2011:2) tapi ingat tingkat kesadaran, tingkat kejujuran, dan tingkat kedisiplinan bangsa Indonesia dalam membayar pajak masih tergolong rendah karena enggan untuk menerapkan kewajiban mereka membayar pajak sesuai dengan ketentuan yang berlaku dan tepat waktu. 
Dalam upaya pengamanan penerimaan negara sangat diperlukan peranan Jurusita Pajak, sebab apabila seluruhnya dilimpahkan kepada wajib pajak, maka pencapaian target belum sepenuhnya terjamin. Dalam melaksanakan penagihan pajak, kinerja Jurusita Pajak dipengaruhi berbagai hal, misalnya terbatasnya jumlah Jurusita Pajak, alamat Wajib Pajak atau Penanggung Pajak tidak diketahui keberadaannya dan sebagainya.

Penilaian kinerja Jurusita Pajak merupakan salah satu penilaian kesuksesan suatu organisasi atau pemerintah yang digunakan untuk mendapatkan optimasi dan dukungan publik, penilaian dilakukan sebagai suatu sarana pembelajaran untuk memperbaiki efektivitas dan potensi kinerja di masa yang akan datang serta untuk mengevaluasi sejauh mana pemerintah menjalankan tugasnya dalam kegiatan pemerintahan, pembangunan daerah, dan pelayanan kepada publik.

Berdasarkan uraian di atas peneliti tertarik untuk mengetahui bagaimana tingkat kinerja Jurusita Pajak dalam melakukan penagihan pajak sebagai sumber pendapatan negara, dengan memilih judul : " efektivitas Kinerja Jurusita Pajak Dalam Melakukan Penagihan Pajak Pada Kantor Pelayanan Pajak Pratama Manado dan Kantor Pelayanan Pajak Pratama Bitung”.

\section{Tujuan Penelitian}

Tujuan penelitian ini adalah untuk mengetahui tingkat efektivitas kinerja Jurusita Pajak dalam pelaksanaan penagihan pajak pada Kantor Pelayanan Pajak Pratama Manado dan Kantor Pelayanan Pajak Pratama Bitung.

\section{Pengrtian Pajak}

\section{TINJAUAN PUSTAKA}

Menurut Brotodiharjo (2011:1), pengertian pajak adalah bantuan, baik secara langsung maupun tidak langsung yang dipaksakan oleh kekuasaan publik dari penduduk atau dari barang, untuk menutupi belanja pemerintah, yang artinya pajak merupakan suatu pemungutan dari masyarakat yang berguna untuk kepentingan negara.

\section{Fungsi Pajak}

Menurut Mardiasmo (2011:1) ada dua fungsi pajak, yaitu sebagai berikut.

1. Fungsi budgetair, yaitu pajak sebagai sumber dana bagi pemerintah untuk membiayai pengeluaran-pengeluarannya.

2. Fungsi mengatur (regulerend), yaitu pajak sebagai alat untuk mengatur atau melaksanakan kebijaksanaan pemerintah dalam bidang sosial dan ekonomi.

\section{Syarat Pemungutan Pajak}

Menurut Mardiasmo (2011:2), syarat pemungutan pajak dibedakan atas lima bagian, yaitu sebagai berikut.

1. Pemungutan pajak harus adil (Syarat Keadilan).

Sesuai degan tujuan hukum, yakni mencapai keadilan, undang-undang dan pelaksanaan pemungutan harus adil. Adil dalam perundang-undangan diantaranya mengenakan pajak secara umum dan merata, serta disesuaikan dengan kemampuan masing-masing. Sedang adil dalam pelaksanaannya yakni dengan memberikan hak bagi Wajib Pajak untuk mengajukan keberatan, penundaan dalam pembayaran dan mengajukan banding kepada Majelis Pertimbangan Pajak.

2. Pemungutan pajak harus berdasarkan undang-undang (Syarat Yuridis).

Di Indonesia, pajak diatur dalam UUD 1945 pasal 23 ayat 2. Hal ini memberikan jaminan hukum untuk menyatakan keadilan, baik bagi negara maupun warganya.

3. Tidak mengganggu perekonomian (Syarat Ekonomis).

Pemungutan tidak boleh mengganggu kelancaran kegiatan produksi maupun perdagangan, sehingga tidak menimbulkan kelesuan perekonomian masyarakat.

4. Pemungutan pajak harus efisien (Syarat Finansiil).

Sesuai fungsi budgetair, biaya pemungutan pajak harus dapat ditekan sehingga lebih rendah dari hasil pemungutnya. 
5. Sistem pemungutan pajak harus sederhana.

Sistem pemungutan yang sederhana akan memudahkan dan mendorong masyarakat dalam memenuhi kewajiban perpajakannya. Syarat ini telah dipenuhi oleh undang-undang perpajakan yang baru.

\section{Dasar Hukum Penagihan Pajak dengan Surat Paksa}

Undang-undang nomor 19 tahun 1997 tentang Penagihan Pajak dengan Surat Paksa sebagaimana telah diubah dengan Undang-undang nomor 19 tahun 2000. Berdasarkan UU Nomor 19 tahun 2000 tentang Penagihan Pajak dengan Surat Paksa, proses tindakan penagihan aktif dimulai dari penerbitan surat teguran, surat paksa, surat pemberitahuan melakukan penyitaan yang dilanjutkan dengan eksekusi sita.

Surat Paksa sekurang-kurangnya meliputi:

1. nama Wajib Pajak, atau nama Wajib Pajak dan Penanggung Pajak;

2. dasar penagihan;

3. besarnya Utang Pajak; dan

4. perintah untuk membayar.

Surat Paksa diterbitkan apabila:

1. penanggung Pajak tidak melunasi utang pajak dan kepadanya diterbitkan surat Teguran atau Surat Peringatan atau surat lain yang sejenis;

2. terhadap Penanggung Pajak telah dilaksanakan penagihan seketika dan sekaligus; atau

3. penanggung Pajak tidak memenuhi ketentuan sebagaimana tercantum dalam keputusan persetujuan angsuran atau penundaan pembayaran pajak.

Surat Paksa terhadap orang pribadi diberitahukan oleh Jurusita Pajak kepada:

1. penanggung pajak;

2. orang dewasa yang bertempat tinggal bersama ataupun bekerja di tempat usaha Penanggung Pajak apabila Penanggung Pajak yang bersangkutan tidak dapat dijumpai;

3. salah satu ahli waris atau pelaksana wasiat atau yang mengurus harta peninggalannya apabila Wajib Pajak telah meninggal dunia dan harta warisan belum dibagi; atau

4. para ahli waris, apabila Wajib Pajak telah meninggal dunia dan harta warisan telah dibagi.

Surat Paksa terhadap badan diberitahukan oleh Jurusita Pajak kepada:

1. pengurus, kepala perwakilan, kepala cabang, penanggung jawab, pemilik modal; atau

2. pegawai tetap di tempat kedudukan atau tempat usaha badan, apabila Jurusita Pajak tidak dapat menjumpai salah seorang sebagaimana dimaksud dalam nomor 1.

Menurut Fauziah (2014), penagihan pajak dengan surat paksa termasuk dalam penagihan pajak yang bersifat aktif, yang merupakan pelaksanaan yang bersifat langsung. Oleh karena itu, sebelum penagihan pajak yang bersifat aktif itu dilakukan, maka terlebih dahulu dilakukan penagihan pajak yang bersifat pasif. Seperti telah disebutkan sebelumnya, penagihan pajak yang bersifat pasif meliputi, penyerahan surat ketetapan pajak dan penerbitan surat teguran/surat peringatan.

\section{Pejabat dan Jurusita Pajak}

Menurut Mardiasmo (2011:125), Pejabat adalah pejabat yang berwenang mengangkat dan memberhentikan Jurusita Pajak, menerbitkan Surat Perintah Penagihan Seketika dan Sekaligus, Surat Paksa, Surat Perintah Melaksanakan Penyitaan, Surat Pencabutan Sita, Pengumuman Lelang, Pembatalan Lelang, Surat Perintah Penyanderaan, dan surat lain yang diperlukan untuk penagihan pajak sehubungan dengan Penanggung Pajak tidak melunasi sebagian atau seluruh utang pajak menurut undang-undang dan peraturan daerah.

Menurut Purnawardhani (2015:3). Jurusita pajak merupakan pihak yang ditunjuk oleh KPP untuk melaksanakan tindakan penagihan aktif. Dalam melaksanakan penyitaan, Jurusita Pajak berwenang memasuki dan memeriksa semua ruangan termasuk membuka lemari, laci, dan tempat lain untuk menemukan objek sita di tempat usaha, di tempat kedudukan, atau di tempat tinggal Penanggung Pajak, atau di tempat lain yang dapat diduga sebagai tempat penyimpanan objek sita. 


\section{Penagihan Seketika dan Sekaligus}

Menurut Mardiasmo (2011:126), penagihan seketika dan sekaligus adalah tindakan penagihan pajak yang dilaksanakan oleh Jurusita Pajak kepada Penanggung Pajak tanpa menunggu tanggal jatuh tempo pembayaran yang meliputi seluruh utang pajak dari semua jenis pajak, Masa Pajak, dan Tahun Pajak. Jurusita Pajak melaksanakan penagihan seketika dan sekaligus berdasarkan Surat Perintah Penagihan Seketika dan Sekaligus. Surat Perintah Penagihan Seketika diterbitkan apabila:

1. penanggung Pajak akan meninggalkan Indonesia untuk selama-lamanya;

2. penanggung Pajak memindahtangankan barang yang dimiliki atau yang dikuasai dalam rangka menghentikan atau mengecilkan kegiatan perusahaan, atau pekerjaan yang dilakukannya di Indonesia;

3. terdapat tanda-tanda bahwa Penanggung Pajak akan membubarkan badan usahanya, atau menggabungkan usahanya, atau memindahtangankan perusahaan yang dimiliki atau dikuasainya, atau melakukan perubahan bentuk lainnya;

4. badan usaha akan dibubarkan oleh Negara; atau

5. terjadinya penyitaan atas barang Penanggung Pajak oleh pihak ketiga atau terdapat tanda-tanda kepailitan.

Surat Perintah Penagihan Seketika dan Sekaligus sekurang-kurangnya memuat:

1. nama wajib pajak, atau nama Wajib Pajak dan Penanggung Pajak;

2. $\quad$ besarnya utang pajak;

3. perintah untuk membayar; dan

4. $\quad$ surat pelunasan pajak.

Surat Paksa.

Surat Perintah Penagihan Seketika dan Sekaligus diterbitkan sebelum penerbitan

\section{Penyitaan}

Menurut Mardiasmo (2011:128), penyitaan adalah tindakan Jurusita Pajak untuk menguasai barang Penanggung Pajak, guna dijadikan jaminan untuk melunasi utang pajak menurut peraturan perundang-undangan.

\section{Daluwarsa Penagihan}

Hak untuk melakukan penagihan pajak, termasuk bunga, denda, kenaikan, dan biaya penagihan pajak, daluwarsa setelah melampaui waktu 5 (lima) tahun terhitung sejak penerbitan Surat Tagihan Pajak, Surat Ketetapan Kurang Bayar, Surat Ketetapan Kurang Bayar Tambahan, dan Surat Keputusan Pembetulan, Surat Keputusan Pembetulan, Surat Keputusan Keberatan, Putusan Banding, serta Putusan Peninjauan kembali.

\section{Teori Efektivitas}

Efektivitas digunakan untuk mengukur dan menunjukkan tingkat keberhasilan serta hubungan yang terjadi terhadap hasil pungutan pajak yang dilakukan oleh Jurusita Pajak.

Rumus pengukuran efektivitas untuk pencairan pelunasan utang pajak adalah sebagai berikut. Efektivitas $=\underline{\text { Realisasi Pelunasan Utang Pajak }} \times 100 \%$

Target Pelunasan Utang Pajak

Untuk mengukur efektivitas, maka digunakan indikator sebagai berikut:

Tabel 1. Klasifikasi Pengukuran Efektivitas

\begin{tabular}{ccc} 
& Persentase & Kriteria \\
\cline { 2 - 3 } & $>100 \%$ & Sangat efektif \\
$90-100 \%$ & Efektif \\
$80-90 \%$ & Cukup efektif \\
$60-80 \%$ & Kurang efektif \\
$<60 \%$ & Tidak efektif \\
\hline
\end{tabular}

Sumber: Depdagri No. 690.900.327 tahun 2006 (dalam Puspitasari: 2014) 
Dari Tabel 1. menunjukkan bahwa apabila persentase yang dicapai lebih dari 100 persen berarti sangat efektif dan apabila persentase kurang dari 60 persen berarti tidak efektif.

\section{Penelitian Terdahulu}

Rifqiansyah (2014) dengan penelitian mengenai analisis efektivitas dan kontribusi penagihan pajak aktif terhadap pencairan tunggakan pajak di KPP Pratama Malang Utara. Jenis penelitian yang digunakan dalam penelitian ini adalah penelitian deskriptif dengan pendekatan study kasus. Hasil penelitian ini menunjukkan bahwa tingkat efektivitas penagihan pajak aktif secara keseluruhan belum cukup dikatakan efektif, selain itu kontribusi penagihan pajak aktif terhadap pencairan tunggakan secara keseluruhan pajak masih sangat kurang. Wardhana (2011) dengan penelitian mengenai efektivitas jurusita pajak dalam pelaksanaan penagihan pajak di KPP Pratama Surakarta. Metode penelitian yang digunakan adalah pembahasan mengenai study kasus yang dilakukan di KPP Pratama Surakarta. Dari hasil penelitian dapat diketahui bahwa kinerja dan Jurusita di KPP Pratama Surakarta sudah cukup efektif dengan tingkat efektivitas melampaui $100 \%$ dan kenaikan pencairan tunggakan pajak yang naik sebanyak $25 \%$.

\section{Jenis Penelitian}

\section{METODE PENELITIAN}

Jenis penelitian yang digunakan adalah deskriptif kuantitatif. Menurut Sedarmayanti (2013:21), penelitian deskriptif adalah penelitian yang bertujuan dalam pencairan fakta status sekelompok manusia, suatu objek, suatu kondisi, suatu sistem pemikiran ataupun suatu peristiwa pada masa sekarang dengan interpretasi yang tepat. Sedangkan menurut Danang (2013:21), data kuantitatif berupa angka atau bilangan yang absolut dapat dikumpulkan dan dibaca relatif lebih mudah.

\section{Tempat dan Waktu Penelitian}

Penelitian ini dilakukan di Kantor Pelayanan Pajak Pratama Manado Jalan Gunung Klabat, Kotak Pos 23, Manado, 95117 dan Kantor Pelayanan Pajak Pratama Bitung Jalan Sam Ratulangi, Bitung, 95511. Waktu pelaksanaan penelitian dimulai pada Februari sampai dengan Maret 2015.

\section{Prosedur Penelitian}

Langkah-langkah yang dilakukan dalam penelitian ini sebagai berikut:

1. Menentukan judul penelitian

2. Menentukan objek penelitian

3. Menyusun proposal

4. Penelitian lapangan

5. Pengumpulan Data

6. Analisis Data Penelitian

7. Kesimpulan dan Saran.

\section{Metode Pengumpulan Data}

Data yang digunakan dalam penelitian ini adalah data primer. Data primer atau data pokok ini adalah data yang diperoleh penulis dengan terjun langsung ke objek penelitian dalam hal ini pengambilan data-data yang berhubungan dengan penulisan penelitian. Data primer yang diperoleh penulis adalah target pelunasan utang pajak dan realisasi pelunasan utang pajak tahun 2014-2015 pada KPP Pratama Manado dan KPP Pratama Bitung.

\section{Metode Analisis}

Analisis data dalam penelitian ini menggunakan analisis rasio efektivitas. Rasio efektivitas menggambarkan kemampuan Jurusita Pajak dalam melakukan penagihan pajak pada Kantor Pelayanan Pajak Pratama Manado dan Kantor Pelayanan Pajak Pratama Bitung. Rumus pengukuran efektivitas untuk pelunasan utang pajak adalah sebagai berikut.

Efektivitas $=$ Realisasi Pelunasan Utang Pajak $\times 100 \%$

Target Pelunasan Utang Pajak 


\section{Defenisi Operasional dan Pengukuran Variabel}

Agar tidak terjadi kesalahan dalam menginterprestasikan judul skripsi ini dan untuk menyatukan persepsi antara penulis dan pembaca maka perlu untuk membahas beberapa hal yang menyangkut definisi operasional yang relevan ditemui dalam penyusunan skripsi ini. Efektivitas kinerja Jurusita pajak adalah suatu gambaran yang menunjukkan tingkat keberhasilan serta hubungan yang terjadi terhadap hasil pungutan pajak yang dilakukan oleh Jurusita pajak.

\section{Hasil Penelitian}

\section{HASIL PENELITIAN DAN PEMBAHASAN}

\section{Sejarah Singkat KPP Pratama Manado}

Kantor Pelayanan Pajak Pratama Manado merupakan instansi vertikal dibawah Kantor Wilayah DJP Sulawesi Utara, Tengah, Gorontalo, dan Maluku Utara yang bernaung dibawah Kementerian Keuangan Republik Indonesia. Tugas pokok dari Kantor Pelayanan Pajak Pratama Manado adalah melaksanakan tugas pokok Direktorat Jenderal Pajak dalam menghimpun penerimaan negara dari sektor perpajakan.

Kantor Pelayanan Pajak berdiri pada tahun 1959, yang merupakan pemecahan dari Kantor Pelayanan Pajak Makassar, dimana pada waktu itu menggunakan istilah Kantor Inspeksi Keuangan. Untuk daerah Sulawesi Utara meliputi Sulut dan Sulteng yang dalam perkembangan selanjutnya pada tahun 1969 diubah menjadi Kantor Inspeksi Pajak dengan wilayah kerja meliputi Sulut dan Sulteng.

\section{Sejarah Singkat KPP Pratama Bitung}

Kantor Pelayanan Pajak Pratama bitung adalah lembaga pemerintahan yang bergerak dibidang pelayanan perpajakan, KPP Pratama Bitung merupakan salah satu kantor cabang Direktorat Jenderal Pajak Departemen Keuangan. Sejak tahun 2002 Direktorat Jenderal Pajak melakukan reformasi birokrasi dan menjadi instansi percontohan reformasi birokrasi dalam memberikan pelayanan prima dan pelaksanaan good governance mengingat kedudukan DJP sebagai instansi yang sangat strategis.

Target dan Realisasi Pelunasan Utang Pajak Pada KPP Pratama Manado dan KPP Pratama Bitung Tahun 2014-2015

Berikut ini Tabel 2 dan Tabel 3 merupakan target dan realisasi pelunasan utang pajak KPP Pratama Manado dan KPP Pratama Bitung tahun 2014-2015.

Tabel 2 Target dan Realisasi Pelunasan Utang Pajak KPP Pratama Manado Tahun 2014-2015

\begin{tabular}{ccc}
\hline Tahun & $\begin{array}{c}\text { Target Pelunasan } \\
\text { Utang Pajak } \\
(\mathrm{Rp})\end{array}$ & $\begin{array}{c}\text { Realisasi Pelunasan Utang } \\
\text { Pajak } \\
(\mathrm{Rp})\end{array}$ \\
\hline 2014 & 39.832 .593 .495 & 22.635 .184 .133 \\
2015 & 61.365 .148 .534 & 31.526 .851 .456 \\
\hline Sumber : KPP Pratama Manado \\
Dari tabel diatas dapat diketahui target dan realisasi pelunasan utang pajak di KPP \\
Pratama Manado tahun 2014-2015. Pada tahun 2014 target penerimaan pajak yang menjadi \\
tanggung jawab Jurusita Pajak pada KPP Pratama Manado adalah sebesar Rp. 39.832.593.495, \\
tetapi yang terealisasi adalah sebesar Rp. 22.635.184.133, sedangkan pada tahun 2015 target \\
penerimaan pajak yang menjadi tanggung jawab Jurusita Pajak pada KPP Pratama Manado \\
adalah sebesar Rp 61,365.148.534 tetapi yang terealisasi adalah sebesar Rp. 31.526.851.456.
\end{tabular}


Tabel 3 Target dan Realisasi Pelunasan Utang Pajak KPP Pratama Bitung

Tahun 2014-2015

\begin{tabular}{ccc}
\hline Tahun & $\begin{array}{c}\text { Target Pelunasan } \\
\text { Utang Pajak } \\
\text { Rp) }\end{array}$ & $\begin{array}{c}\text { Realisasi Pelunasan Utang } \\
\text { Pajak } \\
\text { (Rp) }\end{array}$ \\
\hline 2014 & 21.969 .317 .649 & 10.509 .277 .390 \\
2015 & 16.459 .134 .528 & 10.455 .259 .254 \\
\hline Sumber : KPP Pratama Bitung
\end{tabular}

Dari tabel diatas dapat diketahui target dan realisasi pelunasan utang pajak di KPP Pratama Bitung tahun 2014-2015. Pada tahun 2014 target penerimaan pajak yang menjadi tanggung jawab Jurusita Pajak KPP Pratama Bitung adalah sebesar Rp. 21.969.317.649 dan yang terealisasi adalah sebesar Rp. 10.509.277.390, sedangkan pada tahun 2015 target penerimaan pajak yang menjadi tanggung jawab Jurusita Pajak pada KPP Pratama Bitung adalah sebesar Rp.16.459.134.528, tetapi yang terealisasi adalah sebesar Rp. 10.455.259.254.

\section{Pembahasan}

Tabel 4 Tingkat Efektivitas Kinerja Jurusita Pajak KPP Pratama Manado Tahun 2014-2015

\begin{tabular}{ccccc}
\hline Tahun & $\begin{array}{c}\text { Target Pelunasan } \\
\text { Utang Pajak } \\
(\mathrm{Rp})\end{array}$ & $\begin{array}{c}\text { Realisasi Pelunasan } \\
\text { Utang Pajak } \\
(\mathrm{Rp})\end{array}$ & $\begin{array}{c}\text { Tingkat } \\
\text { Efektivitas } \\
(\%)\end{array}$ & Keterangan \\
\hline 2014 & 39.832 .593 .495 & 22.635 .184 .133 & 56,82 & $\begin{array}{c}\text { Tidak } \\
\text { Efektif } \\
\text { Tidak } \\
2015\end{array}$ \\
\hline
\end{tabular}

Sumber : Data olahan

Dari tabel diatas dapat dilihat tingkat efektivitas kinerja Jurusita Pajak KPP Pratama Manado tahun 2014-2015. Pada tahun 2014 target penerimaan pajak yang menjadi tanggung jawab Jurusita Pajak pada KPP Pratama Manado adalah sebesar Rp. 39.832.593.495, tetapi yang terealisasi adalah sebesar Rp. 22.635.184.133, dan tingkat efektivitas sebesar 56,82\% (tidak efektif), sedangkan pada tahun 2015 target penerimaan pajak yang menjadi tanggung jawab Jurusita Pajak pada KPP Pratama Manado adalah sebesar Rp 61,365.148.534 tetapi yang terealisasi adalah sebesar Rp. 31.526.851.456 dan tingkat efektivitas sebesar 21,63\% (tidak efektif).

Tabel 5 Tingkat Efektivitas Kinerja Jurusita Pajak KPP Pratama Bitung Tahun 2014-2015

\begin{tabular}{lcccc}
\hline Tahun & $\begin{array}{c}\text { Target Pelunasan } \\
\text { Utang Pajak } \\
(\mathrm{Rp})\end{array}$ & $\begin{array}{c}\text { Realisasi Pelunasan } \\
\text { Utang Pajak } \\
(\mathrm{Rp})\end{array}$ & $\begin{array}{c}\text { Tingkat } \\
\text { Efektivitas } \\
(\%)\end{array}$ & Keterangan \\
\hline 2014 & 21.969 .317 .649 & 10.509 .277 .390 & 47,83 & Tidak Efektif \\
2015 & 16.459 .134 .528 & 10.455 .259 .254 & 63,52 & Kurang Efektif \\
\hline \multicolumn{2}{l}{ Sumber $:$ Data olahan }
\end{tabular}

Dari tabel diatas dapat dilihat tingkat efektivitas kinerja Jurusita Pajak KPP Pratama Bitung tahun 2014-2015. Pada tahun 2014 target penerimaan pajak yang menjadi tanggung jawab Jurusita Pajak KPP Pratama Bitung adalah sebesar Rp. 21.969.317.649 dan yang terealisasi adalah sebesar Rp. 10.509.277.390 dan tingkat efektivitas sebesar 47,83\% (tidak efektif), sedangkan pada tahun 2015 target penerimaan pajak yang menjadi tanggung jawab 
Jurusita Pajak pada KPP Pratama Bitung adalah sebesar Rp.16.459.134.528, tetapi yang terealisasi adalah sebesar Rp. 10.455.259.254 dan tingkat efektivitas sebesar 63,52\% (kurang efektif).

\section{Faktor-faktor yang Mempengaruhi Kinerja Jurusita Pajak Tidak Efektif Dalam Melakukan Penagihan Pajak Pada KPP Pratama Manado dan KPP Pratama Bitung.}

Ada beberapa faktor-faktor yang menyebabkan sehingga kinerja Jurusita Pajak tidak efektif dalam melakukan penagihan pajak, yaitu sebagai berikut.

1. Kantor Pelayanan Pajak Pratama Manado:

a. Perusahaan yang akan ditagih sudah tutup.

b. Wajib Pajak tidak mampu melunasi utang pajaknya.

c. Terbatasnya jumlah Jurusita Pajak.

d. Belum ada dukungan dana.

e. Wajib Pajak atau penanggung pajak tidak diketahui keberadaannya.

2. Kantor Pelayanan Pajak Pratama Bitung:

a. Minimnya Jumlah Jurusita Pajak.

b. Tidak ada prognosis dan garis waktu yang jelas dalam pelaksanaan penagihan aktif.

c. Wajib Pajak atau penanggung pajak tidak dapat diketahui keberadaannya.

d. Banyaknya Wajib Pajak yang melakukan upaya hukum (keberatan dan banding).

e. Administrasi tidak lengkap.

\section{PENUTUP}

\section{Kesimpulan}

Penelitian ini dilakukan untuk mengetahui tingkat efektivitas kinerja Jurusita pajak dalam melakukan penagihan pajak di KPP Pratama Manado dan KPP Pratama Bitung. Berdasarkan hasil penelitian dan pembahasan pada bab sebelumnya maka dapat disimpulkan sebagai berikut.

1. Tingkat efektivitas kinerja Jurusita Pajak di Kantor Pelayanan Pajak Pratama Manado pada tahun 2014-2015 dinyatakan tidak efektif. Terbukti dari persentase efektivitas pada tahun 2014 sebesar 56,82\% (tidak efektif) dan pada 2015 sebesar 51,37\% (tidak efektif).

2. Tingkat efektivitas kinerja Jurusita Pajak di Kantor Pelayanan Pajak Pratama Bitung pada tahun 2014-2015 dinyatakan tidak efektif. Terbukti dari persentase efektivitas pada tahun 2014 sebesar 47,83\% (tidak efektif) dan pada tahun 2015 sebesar 63,52\% (kurang efektif).

\section{Saran}

Berdasarkan kesimpulan diatas, maka saran yang dapat dikemukakan sebagai berikut.

1. Kantor Pelayanan Pajak Pratama Manado perlu melakukan tindakan sebagai berikut:

a. mengintensifkan kegiatan pengelompokan penunggak pajak terbesar, agar penagihan pajak lebih efektif;

b. melakukan pengawasan secara intensif terhadap penanggung pajak yang belum melunasi utang pajaknya;

c. menambah Jurusita Pajak dalam melakukan penagihan pajak agar pencairan tunggakan pajak bisa lebih besar, sehingga dapat memenuhi target realisasi pencairan tunggakan pajak, serta memberikan tambahan pendidikan dan pelatihan bagi yang akan menjadi Jurusita Pajak agar meningkatkan kesiapan saat regenerasi;

d. sebaiknya menambah insentif kepada Jurusita Pajak dalam melakukan penyitaan terkait dengan adanya biaya balas jasa dari pihak yang bekerjasama pada saat dilakukan penyitaan; 
e. sebaiknya Jurusita Pajak meningkatkan kerjasama dengan pihak bank, kepolisian, dan aparat pemerintah dalam proses penyitaan; dan

f. perlu mengadakan kerjasama dengan pemerintah daerah untuk memudahkan mencari penanggung pajak yang pindah tanpa pemberitahuan dan alamat yang kurang jelas.

2. Kantor Pelayanan Pajak Pratama Bitung perlu melakukan tindakan sebagai berikut:

a. melakukan perekrutan pegawai khususnya Jurusita Pajak;

b. Jurusita Pajak memperjelas prognosis penagihan utang pajak dengan cara menghimbau, menerbitkan berita acara, serta mengunjungi Wajib Pajak;

c. diharapkan pada saat pendaftaran, Wajib Pajak mencantumkan alamat yang jelas dan ketika ingin pindah sebaiknya melapor dan melakukan perubahan data terbaru;

d. diharapkan Dirjen Pajak lebih teliti dalam proses pengajuan keberatan dan banding yang diajukan oleh Wajib Pajak;

e. sebaiknya Jurusita Pajak melakukan rekap ulang terhadap administrasi Wajib Pajak yang tidak lengkap.

\section{DAFTAR PUSTAKA}

Brotodiharjo, 2011. Pengantar Ilmu Hukum Pajak. PT Rafika Aditama. Bandung.

Danang, Sunyoto, 2013. Metode Penelitian Akuntansi, Indeks. Jakarta.

Fauziah, 2014. Pengaruh Penagihan Pajak dengan Surat Teguran dan Surat Paksa Terhadap Penerimaan Pajak. Jurnal. Tanjungpinang: Fakultas Ekonomi Universitas Maritim Raja Ali Haji.

Lawal, Tolu, Abe Oluwatoyin, 2011. "National development in Nigeria: Issues, challenges and prospects". Journal of Public Administration and Policy Research. 3(9)

Mardiasmo, 2011. Perpajakan Edisi Revisi. ANDI. Yogyakarta.

Purnawardhani, Restika, Amirudin Jauhari, Sri Mangesti Rahayu, 2015. Efektivitas Penagihan Pajak Aktif Dengan Surat Teguran dan Surat Paksa Dalam Upaya Optimalisasi Penerimaan Pajak Di Kantor Pelayanan Pajak Madya Malang. Jurnal Perpajakan. 1(1).

Puspitasari, Ayu Risky Elfayang, 2014. Analisis Efektivitas, Efisiensi, dan Kontribusi Pajak dan Retribusi Daerah Terhadap PAD Kabupaten Blora Tahun 2009-2013. Fakultas Ekonomi dan Bisnis Universitas Diponegoro Semarang.

Rifqiansyah, Hasbi, Devi Farah Azizah, Muhammad Saifi, 2014. Analisis Efektivitas Dan Kontribusi Penagihan Pajak Aktif Terhadap Pencairan Tunggakan Pajak Di KPP Pratama Malang Utara. Jurnal. Malang 15(1)

Sedarmayanti, Hidayat Syarifudin, 2011. Metodologi Penelitian. Mandar Maju. Bandung.

Wardhana, Asoka Okky. 2011. Efektivitas Jurusita Pajak Dalam Pelaksanaan Penagihan Pajak Di KPP Pratama Surakarta. Jurnal. Surakarta: Universitas Sebelas Maret. 